
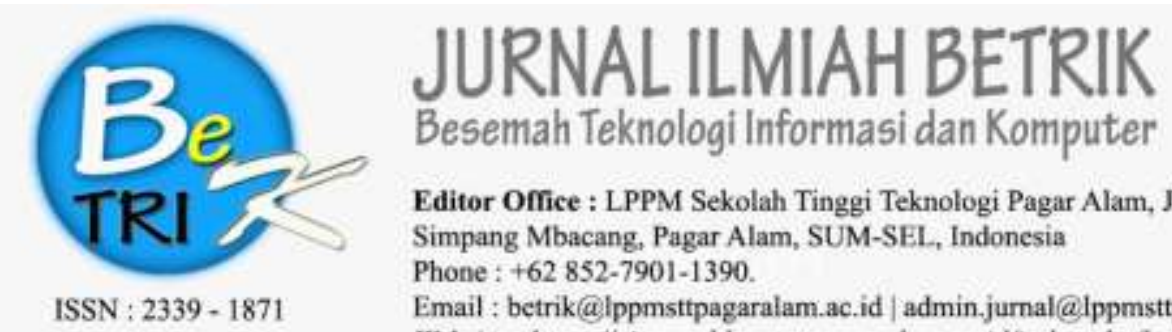

Editor Office : LPPM Sekolah Tinggi Teknologi Pagar Alam, Jn. Masik Siagim No. 75 Simpang Mbacang, Pagar Alam, SUM-SEL, Indonesia Phone: +62 852-7901-1390.

Email : betrik@lppmsttpagaralam.ac.id / admin.jurnal@lppmsttpagaralam.ac.id Website : hups:/lejournal.lppmsttpagaralam.ac.id/index.php/betrik/index

\title{
Implementasi Jaringan Tunnel Berbasis Eoip (Ethernet Over Ip ) Dengan Mikrotik Router Rb 2011 Il-Rm Di Silampari Tv Lubuklinggau
}

\author{
Armanto \\ Dosen Teknik Informatika STMIK MUSIRAWAS Lubuklinggau \\ Jl. Jendral Besar H.M Soeharto KM. 13 Kel. Lubuk Kupang Kec. Lubuklinggau Selatan I \\ Kota Lubuklinggau Sumatera Selatan Telp: (0733) 3280300 \\ Email : Armansatan@yhaoo.co.id
}

\begin{abstract}
Designing an Eoip-Based Tunnel Network (Ethernet Over Ip) With Mikrotik Router Rb 2011 Il-Rm In Silampari Tv Lubuklinggau, compiled by armanto, Currently in Silampari Tv has two buildings in the suburbs That has two offices in different places with the distance Far enough, the first office in one studio is precisely located in Watervang and the two studios are in Sumber Agung Kota Lubuklinggau. In studio one is a production kitchen that processes video to run. Not connected to each other, so between studio one and setudio two can not do file sharing, VOIP, and the need for information exchange in other networks. Therefore I will create a computer network that can overcome the problems that have been complained by the Silampari TV by using MikroTik as its main tool and provide a solution that is quite economical and reliable for this problem, one of them with Tunnel. In this research used some tools like 6 unit pc which is used for client, swich as data communication media between utp cable, TP-Link Wireless Router fruit as hotspot and data distribution media from mikrotik one to mikrotik two, and two mikrotik rb 11 for Internet data and tunnel settings, Inteernet that supports this research is that can from one of the providers in the hole linggau namely B-NET
\end{abstract}

Keywords: Tunnel, Eoip, Mikrotik

Abstrak : Rancang Bangun Jaringan Tunnel Berbasis Eoip (Ethernet Over Ip ) Dengan Mikrotik Router Rb 2011 Il-Rm Di Silampari Tv Lubuklinggau, disusun oleh armanto, Pada saat ini di Silampari Tv memiliki Dua buah Gedung dilubuklinggau Yaitu memiliki dua kantor di tempat yang berbeda dengan jarak yang cukup jauh, kantor pertama pada studio satu tepatnya terletak di Watervang dan studio dua berada di Sumber Agung Kota Lubuklinggau. Pada studio satu merupakan dapur produksi yang mengolah video untuk ditayangkan. Tidak saling terkoneksi, sehingga antara studio satu dan setudio dua tidak bisa melakukan file sharing, VOIP, dan kebutuhan pertukaran informasi dalam jaringan lainnya. Maka dari itu saya akan membuat sebuah jaringan komputer yang bisa mengatasi permasalahan yang selama ini di keluhkan oleh pihak Silampari TV dengan menggunakan MikroTik sebagai alat utamanya dan memberikan solusi yang cukup ekonomis dan reliable untuk masalah ini, salah satunya dengan Tunnel. Pada penelitian ini digunakan beberapa alat seperti 6 unit pc yang digunakan untuk client, swich sebagai media komunikasi data antar kabel utp, buah Wireless Router TP-Link 
sebagai hotspot dan media penyaluran data dari mikrotik satu ke mikrotik dua, dan dua buah mikrotik rb 11 untuk pengaturan data internet dan tunnel, Internet yang mendukung penelitian ini adalah yang di dapat dari salah satu provider yang ada di lubuk linggau yaitu $B-N E T$

Kata Kunci : Tunnel, Eoip, Mikrotik

\section{PENDAHULUAN}

Jaringan komputer di era modern ini telah meluas hingga membentuk jaringan core yang banyak disetiap negara untuk dapat saling terhubung atau sering disebut internet. Dengan internet pengguna dapat berinteraksi satu sama lain di tempat yang berbeda. Sekarang jaringan komputer dapat diakses menggunakan perangkat mobile seperti handphone pintar.

Seiring perkembangan teknologi, jaringan komputer dibutuhkan sebagai media komunikasi masal yang umum digunakan. Dengan adanya jaringan komputer, pengguna yang terhubung ke jaringan dapat saling bertukar informasi data dan sumber daya seperti printer, scanner, dan lain-lain.

Jaringan komputer telah banyak digunakan di instansi pemerintahan dan perkantoran bahkan jaringan komputer seperti internet merupakan kebutuhan utama sebagai alat komunikasi untuk bertukar data dan mengirim surat elektronik.

Seperti pada kantor Silampari Tv, merupakan perusahaan yang bergerak dibidang pertelevisian dan media informasi, memiliki dua kantor di tempat yang berbeda dengan jarak yang cukup jauh, kantor pertama pada studio satu tepatnya terletak di Watervang dan studio dua berada di Sumber Agung Kota Lubuklinggau. Pada studio satu merupakan dapur produksi yang mengolah video untuk ditayangkan. Pada studio satu terdapat komputer editor, jurnalis, kameramen, dan komputer server. Pada studio dua terdapat komputer master control yang berfungsi menayangkan video yang telah diedit.

Selama ini sebelum data video tersebut ditayangkan, data video disimpan didalam hardisk dan harus diantar dengan kendaraan bermotor ke studio dua, hal ini tentu akan memakan waktu dan biaya, belum lagi bila terjadi kendala pada kendaraan saat dijalan akan berdampak pada penundaan jam tayang program acara. Untuk mengantisipasi hal ini maka diperlukan sebuah media, berupa jaringan untuk menghubungkan kedua kantor tersebut. Berdasarkan hal diatas maka penulis tertarik untuk melakukan penelitian pada kantor tersebut dengan judul "Jaringan Tunnel Berbasis EOIP (Ethernet Over Ip) Dengan Mikrotik Router di Silampari Tv".

\section{METODOLOGI PENELITIAN}

\subsection{Analisis dan Desain Sistem}

Dalam pembuatan jaringan, peneliti menganalisa data yang telah dikumpulkan dari masalah yang didapat pada lapangan. Jaringan Silampari $\mathrm{Tv}$ menggunakan ISP (Internet Service Provider) B-Net, yang menggunakan koneksi jaringan nirkabel point to point untuk 
tehubung ke central node. ISP memberikan Ip public lokal yang hanya dapat diakses oleh sesama pengguna ISP B-Net yang terkoneksi secara point to point menggunakan jaringan nirkabel.

Dengan kata lain, Silampari Tv menggunakan infrastruktur jaringan MAN (Metropolitan Area Network) yang telah disediakan oleh ISP B-Net. Untuk keamanan pertukaran data pada studio satu dan studio dua akan dibuat protokol EOIP Tunnel yang memungkinkan Ip public pengguna ISP B-Net yang lain tidak dapat mengakses jaringan lokal studio satu dan studio dua Silampari Tv.

\section{a. Sistem Lama}

Pada sistem lama, "jaringan lokal studio satu dan studio dua tidak dapat terhubung" dan hanya kedua router saja yang saling berkomunikasi dengan menggunakan ip public yang didapat dari ISP.

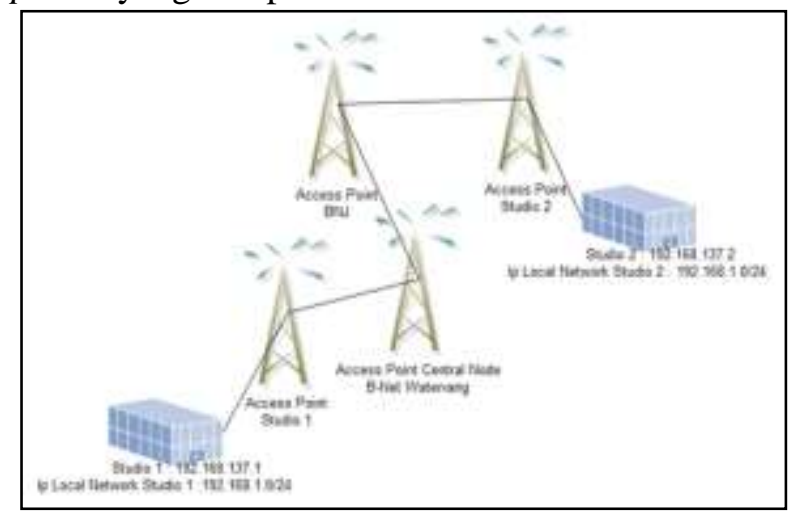

\section{Gambar 1. Desain Jaringan Lama}

\section{b. Sistem Baru}

Pada sistem baru yang akan dibuaat komputer pada studio satu dan studio dua Silampari Tv dapat terhubung menggunakan jaringan tunnel dengan dua range ip yang berbeda. Ip range pada studio satu adalah 192.168.1.0/24 dan range ip studio dua adalah 192.168.2.0/24.

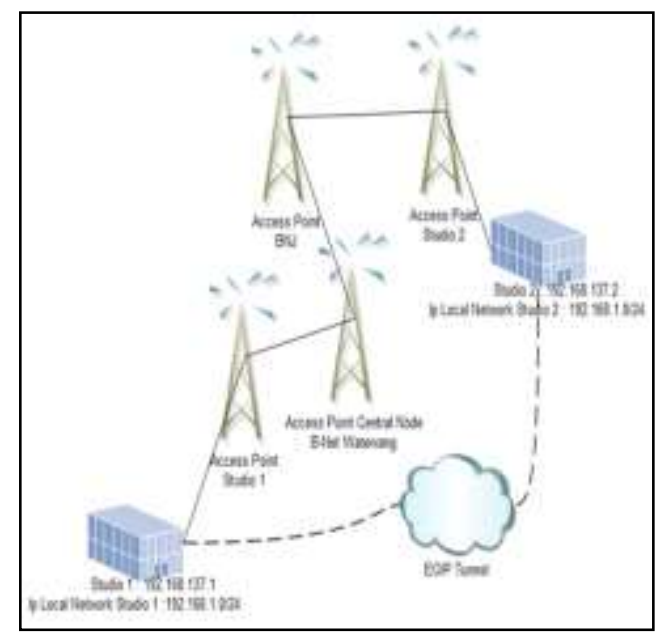

Gambar 2. Desain Jaringan baru

\subsection{Perancangan dan Desain Jaringan}

Tahap perancangan adalah tahap terpenting, untuk mendapatkan hasil yang maksimal. Pada tahap ini diperlukan ketelitian yang baik dan tepat sebagai langkah awal dari rancang bangun jaringan yang akan dibuat sehingga dapat memperhitungkan biaya yang harus dikeluarkan dan meminimalisir terjadinya kegagalan.

Jaringan tunnel berbasis EOIP dengan mikrotik router di Silampari TV, penulis menarik kesimpulan dan menghasilkan rancang bangun skema jaringan yang dibuat nantinya seperti pada gambar berikut. 


\section{Gambar 4. Topologi jaringan Silampari Tv}

\section{Gambar 3. Diagram blok sistem}

\subsection{Perancangan Topologi Jaringan}

Topologi adalah suatu tehnik untuk menghubungkan komputer yang satu dengan komputer lainnya sehingga terangkai menjadi sebuah jaringan, dimana penggunaan topologi jaringan didasarkan pada biaya, kecepatan akses data, ukuran maupun tingkat konektivitas yang akan mempengaruhi kualitas maupun efisiensi suatu jaringan (Irianto, 2014, Pengertian dan Jenis-jenis Topologi Jaringan : 1). Pada perancangan Jaringan Tunnel Berbasis EOIP Dengan Mikrotik Router di Silampari TV akan dilakukan simulasi rancangan jaringan menggunakan dua access point, dua router dan empat komputer seperti gambar 3.5.

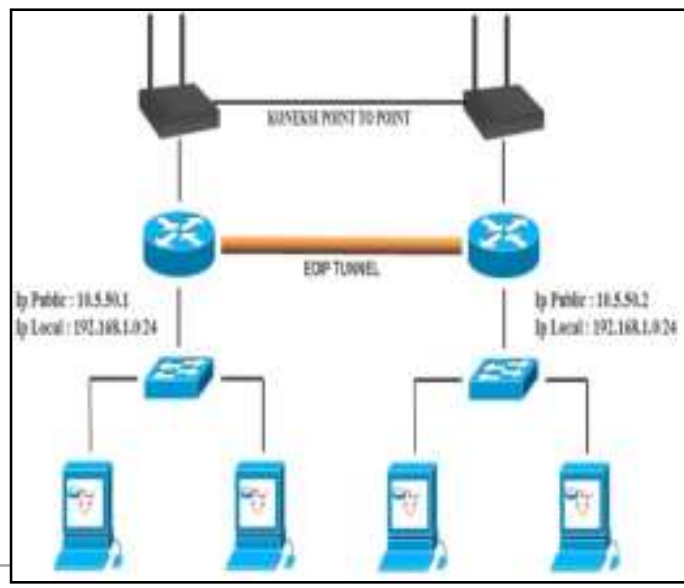

\section{Server}

Server diibarat sebagai pelayan yang memiliki hak untuk mengatur. Server disebut sebagai pelayan dikarenakan fungsi server secara keseluruhan adalah memberi layanan (service) kepada client yang saling terhubung satu sama lain dalam satu jaringan. Sedangkan fungsi server dalam mengatur adalah bagaimana server mengatur dalam memberi hak akses terhadap client yang terhubung dengan server tersebut. Contohnya hak akses internet, akses directory, dan lain-lain.

Menurut Winarno dan Zaki (2013:5) Server adalah komputer pemilik hard drive, printer dan resource lain yang member layanan di jaringan.

Menurut Purbo (2008:2) Server merupakan komputer yang multiuser yang memberikan jasa (seperti akses database, file transfer, remote akses) atau memberikan sumber daya (seperti file yang besar) melalui sambungan di jaringan komputer.

Menurut Sopandi (2004:7) Server adalah sebuah komputer yang berisi program, baik sistem operasi maupun program aplikasi yang menyediakan pelayanan kepada komputer atau program lain yang sama ataupun berbeda. Komputer server adalah komputer yang biasanya dikhususkan untuk penyimpanan data atau sebagai basis data. Selain itu, jika 
menggunakan sistem operasi berbasis network (Network Operating System), berisikan daftar user yang diperbolehkan masuk ke server tersebut. Dalam model programming client/server, server adalah program-program yang menunggu dan memenuhi permintaan dari client program yang sama atau berbeda.

\section{Voice Over Internet Protokol (VoIP)}

Voice over Internet Protokol (VoIP) dikenal juga dengan sebutan IP Telephony didefinisikan sebagai suatu sistem yang menggunakan jaringan internet untuk mengirimkan paket suara dari suatu tempat ke tempat lain menggunakan perantara protokol IP (Internet Protokol). Dengan kata lain teknologi ini mampu melewatkan trafik suara yang berbentuk paket melalui jaringan IP.

Menurut Febrian (2004) Voice Over Internet Protocol adalah suatu mekanisme untuk melakukan pembicaraan telepon (voice) dengan menumpangkan data dari pembicaraan melalui internet atau intranet (yang menggunakan teknologi IP).

Menurut Sugeng (2008:1) VOIP dikenal juga dengan sebutan IP Telephony adalah suatu sistem yang menggunakan jaringan Internet untuk mengirimkan data paket suara dari suatu tempat ke tempat yang lain menggunakan perantara protokol IP. Sehingga perbedaan VoIP dengan telepon tradisional adalah masalah infrastukturnya, jika VoIP menggunakan Internet sedangkan telepon tradisional menggunakan infrastruktur telepon yang sudah dibangun lebih awal.

\section{Jaringan Komputer}

Dewasa ini, jaringan komputer menjadi salah satu bidang yang mendukung perkembangan teknologi. Tidak bisa dipungkiri, peran serta jaringan komputer dalam perkembangan teknologi di dunia sangatlah berdampak besar. Tanpa adanya jaringan komputer, mungkin dunia akan kesulitan dalam mengakses informasi, data, bahkan untuk berkomunikasi.

Menurut Kurniawan (2007:2) jaringan komputer adalah kumpulan sejumlah peripheral yang terdiri dari beberapa komputer, printer, LAN card, dan peralatan lain yang saling terintegrasi satu sama lain. Dengan demikian, kita dapat melakukan aktivitas seperti tukar menukar data atau informasi dengan mudah dan dalam waktu singkat dan cepat.

Menurut Sofana (2013:3) jaringan komputer adalah kumpulan beberapa komputer (dan perangkat lain seperti router, switch dan sebgainya) yang saling terhubung satu sama lain melalui perantara.

Menurut Sopandi (2004:1) jaringan komputer merupakan gabungan antara teknologi komputer dan teknologi komunikasi.

\section{Internet Protokol (IP)}


Menurut Sofana (2013:94) Internet protocol adalah protocol yang mengatur bagaimana suatu data dapat dikenal dan dikirim dari satu komputer ke komputer lain. IP bersifat connectionless protocol. Hal ini berarti IP tidak melakukan error detection dan error recovery. IP tidak dapat melakukan handshake (pertukaran control informasi) saat membangun sebuah koneksi, sebelum data dikirim. Padahal handshake merupakan salah satu syarat agar sebuah koneksi baru dapat terjadi. Dengan demikian, IP bergantung pada layer lainnya untuk melakukan handshake.

Menurut Kurniawan (2007:6) Internet protocol merupakan salah satu protokol atau standard aturan jaringan yang sering digunakan pada jaringan berskala besar dan luas.

Menurut Zam (2014:55) Internet protocol adalah alamat unik yang diberikan pada komputer dalam sebuah jaringan. Disebut unik karena satu alamat hanya boleh dimiliki oleh satu komputer.

\section{Topologi Jaringan Komputer}

Menurut Madcom (2009:4) Topologi jaringan merupakan gambaran pola hubungan antara komponen-komponen jaringan, yang meliputi komputer server, komputer client/workstation, hub/Switch, pengkabelan, dan komponen jaringan lainnya.

Menurut Sofana (20013:7) Topologi jaringan merupakan suatu aturan atau rules bagaimana menghubungkan jaringan komputer secara fisik.
Menurut Kurniawan (2007:25) Topologi jaringan merupakan arsitektur fisik jaringan yang bertujuan agar apabila sutau saat jaringan tersebut ingin kita kembangkan menjadi suatu jaringan dengan skala lebih besar dan luas maka pemasangan maupun perawatan jaringan menjadi lebih mudah. Ada 5 macam dari topologi jaringan yaitu sebagai berikut:

1. Topologi Bus

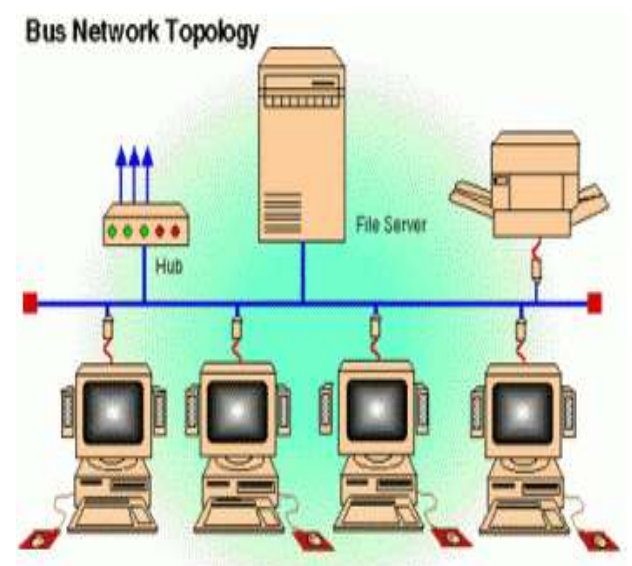

Gambar 5. Topologi Bus

2. Topologi Token Ring (Ring)

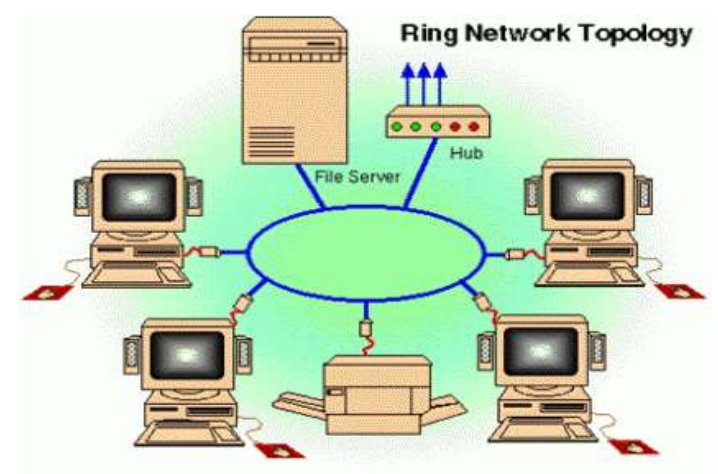

Gambar 6. Topologi Ring

3. Topologi Star 


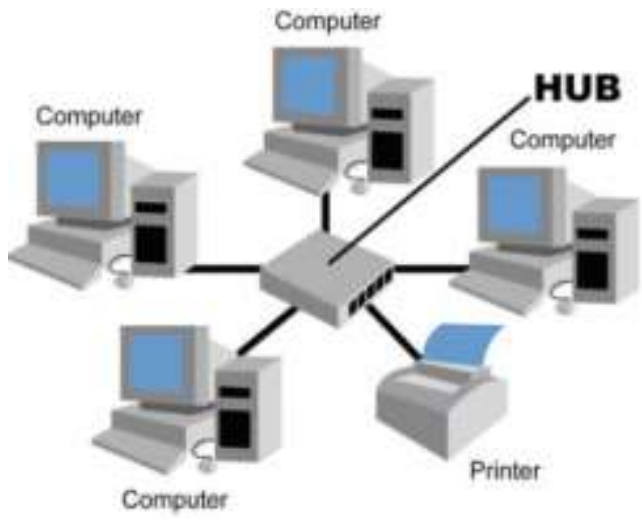

Gambar7. Topologi star

4. Topologi Mesh

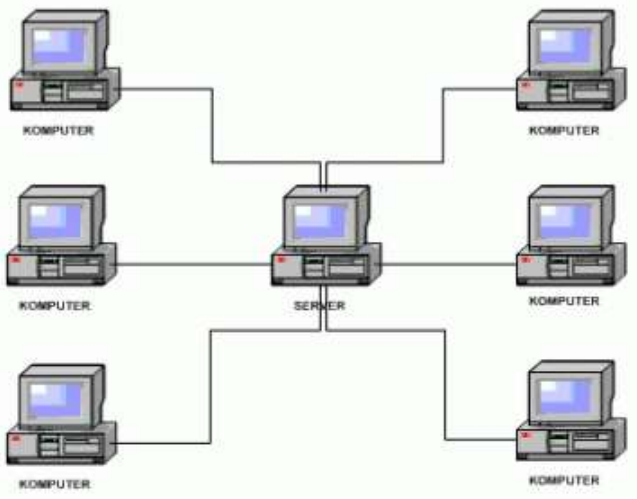

Gambar 8.Topologi mesh

\section{Hotspot}

Menurut Sofana (2013:445) Hotspot adalah area akses internet menggunakan teknologi 802.11b yang dapat dinikmati oleh pengguna. Anda dapat membawa laptop atau PDA ke area hotspot dan melakukan akses internet memanfaatkan Wi-Fi adapter.

Menurut Mulyanta (2005:148) Hotspot adalah sebuah kawasan yang menyediakan ketersediaan koneksi jaringan tanpa kabel di mana user menggunakan perlengkapan yang kompatibel untuk dapat melakukan koneksi internet atau ke intranet, aktivitas e-mail dan aktivitas jaringan lain.
Menurut Zam (2014:182) Hotspot adalah sebuah teknologi autentikasi yang biasa digunakan ketika kita akan menyediakan akses internet pada area public.

\section{Kartu Jaringan (LAN CARD)}

Menurut Kurniawan (2007:38) kartu jaringan merupakan perangkat paling utama yang harus terpasang pada komputer kita. Setiap komputer dapat kita hubungkan dengan suatau jaringan melalui kartu jaringan. Dengan adanya kartu jaringan, proses tukar- menukar data atau informasi antara satu komputer dengan yang lainnya dapat terjadi.

Menurut Sopandi (2004:10) Kartu jaringan (LAN Card) adalah sebuah kartu yang dipasang pada slot ekspansi pada sebuah motherboard komputer sehingga komputer dapat dihubungkan ke dalam sistem jaringan.

Menurut Febrian (2004:455) Kartu Jaringan (LAN Card) adalah kartu yang digunakan untuk mendukung komputer bisa terhubung dalam satu jaringan.

\section{Access Point}

Menurut Kurniawan (2007:58) Access point merupakan alat terpenting dalam membangun jaringan wireless maupun jaringan hostpot. Pada dasarnya access point merupakan hub untuk wireless dan brigde untuk jaringan LAN UTP. Oleh karena itu, biasanya pada access point terdapat port untuk konektor RJ45. Untuk menghindari collision atau tabrakan data baik yang diterima maupun yang dikirim, access point menggunakan media access Carrier Sense Multiple Access with Collision 
Avoidence atau biasa disebut dengan CSMA/CA.

Menurut Mulyanta (2005:54) Access point adalah alat atau perangkat yang digunakan untuk melakukan pengaturan lalu lintas jaringan dari mobile radio ke jaringan kabel atau backbone jaringan wireless client/server.

Menurut Sofana (2013:338) Access point bertugas mengatur dan menghubungkan koneksi beberapa peralatan Wi-Fi. Access point dapat dianalogikan dengan $h u b$, hanya saja digunakan pada wireless LAN.

\section{Mikrotik Router}

Mikrotik RouterOS TM adalah sistem operasi dan perangkat lunak yang dapat digunakan untuk menjadikan komputer manjadi router network yang handal, mencakup berbagai fitur yang dibuat untuk ip network dan jaringan wireless, cocok digunakan oleh ISP dan provider hotspot (mikrotik.co.id).

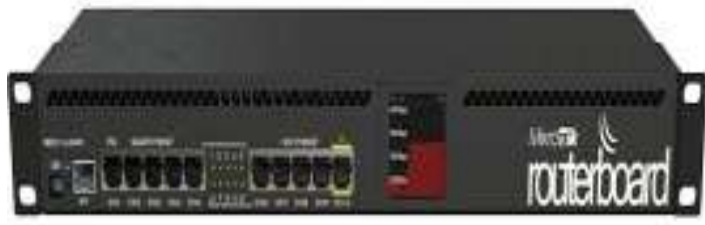

Gambar 9. Mikrotik Router Board

\section{HASIL}

\subsection{Pengujian Transfer Data Menggunakan} File Sharing

File sharing merupakan cara pertukaran data yang umum dilakukan pada jaringan. Untuk melakukan file sharing dapat dilakukan dengan langkah sebagai berikut :

1. Buatlah satu folder pada komputer studio satu

2. Klik kanan dan pilih properties pada folder yang baru dibuat tersebut.

3. Pada tab sharing beri chek list pada opsi share this folder on the network dan Allow to user change my files.

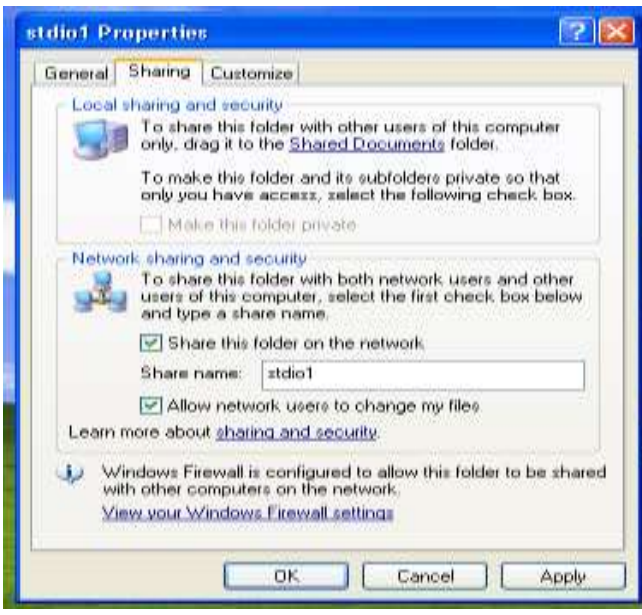

Gambar 10. Folder properties pada tab sharing

Ketika sharing folder berhasil dilakukan, pada tahap berikutnya folder yang telah di sharing akan diakses oleh komputer studio dua dengan cara mengaksess ip komputer studio satu dengan format \192.168.1.2 pada address bar windows explorer, hasilnya dapat dilihat pada gambar 10.

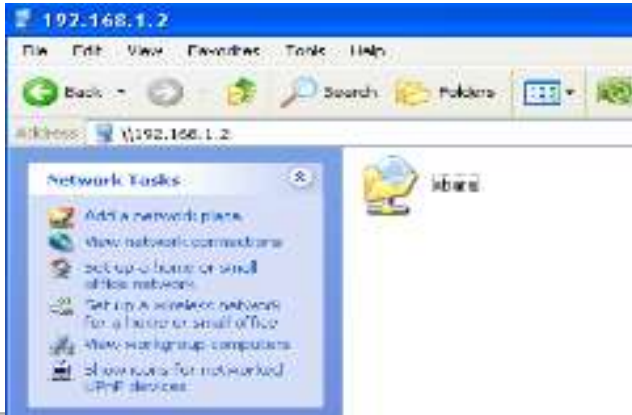




\section{Gambar 11. Tampak folder yang disharing dari komputer studio satu}

Untuk menguji apakah folder yang di sharing dari komputer studio satu dapat menerima data dari komputer studio dua dilakukan copy data ke folder sharing tadi dan apabila berhasil akan ada proses copy seperti gambar 12 Sebelum transfer data berjalan dipastikan kapasitas hardisk masih luas dan permission folder allow untuk semua user.

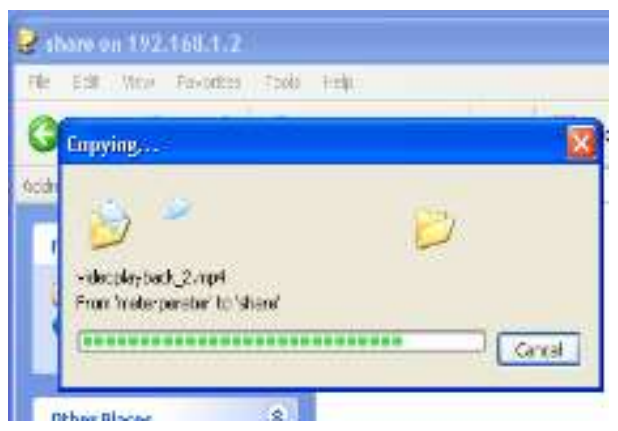

\section{Gambar 12. Proses copy file di folder sharing komputer studio satu.}

\subsection{Hasil Monitoring Pengiriman Data}

Pengiriman data akan dilakukan dari komputer pada router 1 ke komputer pada jaringan lokal router 2. Tools yang digunakan adalah tourch yang merupakan tools bawaan winbox.

Akan ada dua interface untuk dilakukan monitoring. Yang pertama adalah interface ether 1 yang terhubung ke radio wireless atau access point dan yang kedua interface tunnel yang telah dibuat.

\subsubsection{Hasil Monitoring Pada Router 1}

Monitoring yang pertama akan dilakukan pada interface router 1, dimana komputer yang berada dalam satu jaringan lokal dengan router 1 mengirim data pada komputer yang berada di jaringan router 2 .

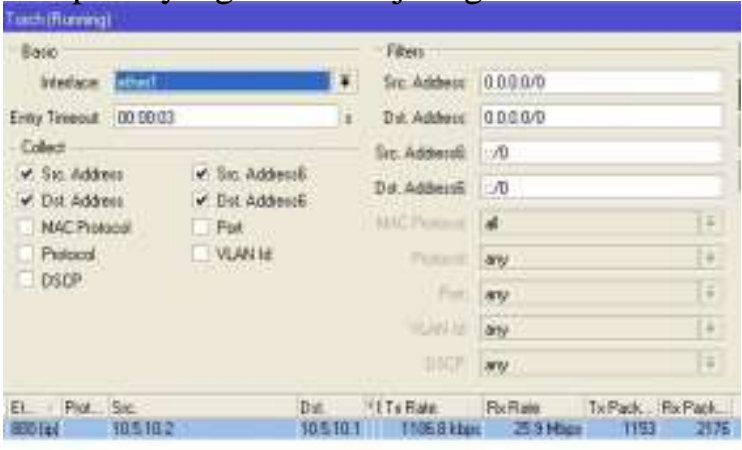

Gambar 13. Hasil monitoring interface ether 1 pada router 1

Pada gambar 13 adalah hasil monitoring torch dari interface ether 1 ketika komputer yang satu jaringan lokal dengan router 1

mengirim data pada komputer yang berada pada jaringan lokal router 2. Terlihat $\mathrm{Tx}$ (Transmit Rate) 1106.8kbps lebih kecil dari pada Rx (Transmit Rate) 25.9Mbps hasil ini mewakili kecepatan perpindahan data atau receive oleh destination address yang melewati interfa ce ether 1 router 1 .

\subsubsection{Hasil Monitoring Pada Router 2}

\begin{tabular}{|c|c|c|c|c|c|}
\hline \multicolumn{6}{|l|}{ Tosilingro } \\
\hline \multicolumn{4}{|l|}{ Bnic } & \multicolumn{2}{|l|}{ Fles: } \\
\hline intersce: shel & & & $\pi$ & Sectudbent & 02000 \\
\hline Enog Insove. 00000 & & & $x$ & Desadben: & 00000 \\
\hline \multicolumn{4}{|l|}{ Colest } & 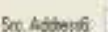 & 8 \\
\hline T Se Adthes: & \multicolumn{3}{|l|}{ Tro Adserso } & Desctinef & $-A$ \\
\hline$\checkmark$ Dit Adder & $\nabla D \geqslant$ Astors 5 & & & Wh Rowerisa & $\pi$ \\
\hline MACForiood & fout & & & 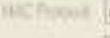 & $\alpha$ \\
\hline \multirow{2}{*}{$\begin{array}{l}\text { Podred } \\
\text { OSUP }\end{array}$} & C MaNid & & & hoopt & 50 \\
\hline & & & & $\tan 1$ & me \\
\hline & & & & rowit & 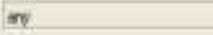 \\
\hline & & & & ais 1 & ay \\
\hline E1 Pad Sis & Dit & $Y D$ & Ta Plas: & is $\quad$ AxR & Ne TxPadk fla Pack \\
\hline antel tosiot. & 105102 & Dost & & conter & $433401 \quad 2191 . \quad 1154$ \\
\hline
\end{tabular}




\section{Gambar 14. Hasil monitoring torch interface ether 1 pada router 2}

Pada gambar 14 adalah hasil monitoring torch dari interface ether 1 ketika komputer yang satu jaringan lokal dengan router 2 menerima data dari komputer yang berada pada jaringan lokal router 1 . Terlihat Rx (Transmit Rate) 26.0Mbps lebih besar dari pada Rx (Transmit Rate) 1121.3kbps hasil ini mewakili kecepatan mengunduh data atau tansmit oleh source address yang melewati interface ether 1 router 2 .

\section{KESIMPULAN}

Adapun kesimpulan dari pembuatan Jaringan Tunnel Berbasis EOIP (Ethernet Over IP) Dengan Mikrotik Router di Silampari Tv :

a. Dengan menggunakan metode tunnel EOIP memungkinkan komputer pada studio satu dan studio dua menjadi satu jaringan lokal.

b. Kantor Silampari Tv melakukan pertukaran data antara komputer menggunakan file sharing. c. Gangguan internal yang kemungkinan akan terjadi ketika melakukan penarikan data antara komputer studio satu dan komputer studio dua adalah saat aktifitas pada jaringan sedang padat pada salah satu studio dan masalah externalnya ketika ISP sedang mengalami perbaikan.

\section{RUJUKAN}

Kurniawan, Wiharsono. 2007. Jaringan Komputer. Yogyakarta: C.V Andi Offset. Madcom. 2009. Membangun Sistem Jaringan Komputer. Yogyakarta: Penerbit Andi.

Mario Tommi Poltak. 2006. Tuntunan Praktis Menguasai Jaringan Komputer. Yogyakarta: Penerbit Ardana Media. 
Mulyanta, Edi S. 2005. Pengenalan Protokol Jaringan Wireless Komputer. Yogyakarta: CV ANDI OFFSET.

Sofana, Iwan. 20013. Membangun Jaringan Komputer. Bandung: Informatika. 